\title{
Health-related productivity losses increase when the health condition is co-morbid with psychological distress: findings from a large cross-sectional sample of working Australians
}

\author{
Libby Holden ${ }^{1 *}$, Paul A Scuffham ${ }^{1}$, Michael F Hilton ${ }^{2}$, Robert S Ware ${ }^{3}$, Nerina Vecchio ${ }^{1}$ and Harvey A Whiteford ${ }^{3}$
}

\begin{abstract}
Background: The health condition of workers is known to impact on productivity outcomes. The relationship between health and productivity is of increasing interest amid the need to increase productivity to meet global financial challenges. Prevalence of psychological distress is also of growing concern in Australia with a two-fold increase in the prevalence of psychological distress in Australia from 1997-2005.
\end{abstract}

Methods: We used the cross-sectional data set from the Australian Work Outcomes Research Cost-benefit (WORC) study to explore the impacts of health conditions with and without co-morbid psychological distress, compared to those with neither condition, in a sample of approximately 78,000 working Australians. The World Health Organisation Health and Performance Questionnaire was used which provided data on demographic characteristics, health condition and working conditions. Data were analysed using negative binomial logistic regression and multinomial logistic regression models for absenteeism and presenteeism respectively.

Results: For both absenteeism and presenteeism productivity measures there was a greater risk of productivity loss associated when health conditions were co-morbid with psychological distress. For some conditions this risk was much greater for those with co-morbid psychological distress compared to those without.

Conclusions: Co-morbid psychological distress demonstrates an increased risk of productivity loss for a range of health conditions. These findings highlight the need for further research to determine whether co-morbid psychological distress potentially exacerbates lost productivity.

\section{Background}

Workers' health impact on absenteeism and presenteeism Health related productivity loss is a concern to researchers, policy makers and industry. There is a growing body of evidence regarding the impact of health conditions on work performance [1-9]. It has been repeatedly found that health conditions increase work-related absences (absenteeism) and/or decrease productivity while at work (presenteeism), creating a substantial economic burden on industry [1-11]. Studies that have considered presenteeism have found it accounts for a greater

\footnotetext{
* Correspondence: I.holden@griffith.edu.au

'School of Medicine, Griffith University; University Drive Meadowbrook, Queensland 4131, Australia

Full list of author information is available at the end of the article
}

proportion of the productivity loss than absenteeism $[11,12]$. For example the associated absenteeism by chronic condition ranged from 0.9 to 5.9 hours in a 4-week period, whereas on-the-job work impairment ranged from a $17.8 \%$ to $36.4 \%$ decrement in ability to function at work. The total cost of chronic conditions was estimated to be $10.7 \%$ of the total labour costs with $6.8 \%$ attributable to work impairment alone [11].

\section{Growing rates of co-morbidity}

International research demonstrates a growing prevalence of co-morbidity, reporting that prevalence increases significantly with age [13-15]; and indicating that patients with co-morbidity in general practice represent the rule rather than the exception [15]. For

\section{C) Biomed Central}


example, Fortin et al. reported the prevalence of having 2 or more health conditions in the 18-to 44-year, 45-to 64-year, and 65-year and older age-groups was, respectively, $68 \%, 95 \%$, and $99 \%$ among women and $72 \%, 89 \%$, and $97 \%$ among men [13].

\section{Co-morbid psychological distress worsens health and productivity outcomes}

There is now considerable evidence that psychological distress is often co-morbid with other health conditions and can worsen health outcomes [16-22]. High levels of psychological distress is a key indicator of mental health problems and is highly correlated with the presence of a diagnosable mental disorder, particularly depression [20]. Psychological distress, as used here, refers to subjective emotional distress [20] expressed by symptoms of depression, anxiety, acute grief reactions, and various other mental health conditions. Psychological distress is highly prevalent in the community, as are mental health disorders. The Australian Bureau of Statistics reported that in the 2004-05 snapshot of mental health and wellbeing in Australian 13\% of adults reported experiencing high/very high levels of psychological distress in the previous four weeks [23]. This report does not account for prevalence in adolescents. There is limited data available on the impact of psychological distress on productivity; however, as psychological distress is a strong indicator for a diagnosable mental disorder $[20,24]$, we draw on literature exploring the effects of psychological distress as well as depression on productivity. Psychological distress has a negative impact on working capacity [20]. Co-morbid depression is associated with significantly increased disability days, [18,25] reduced likelihood of working full-time and increased likelihood of reduced productivity [25].

\section{Gaps in literature demonstrate the need for further research on the impacts of co-morbid psychological distress on productivity decrements}

There is strong evidence that a large number of adults with a disease have co-morbid psychological distress (PD) or depression. Few studies have considered the impact of disease co-morbid with PD impacting on productivity [25-27]. This study aims to address this gap in knowledge by exploring the impacts on absenteeism and presenteeism for a range of health conditions with and without co-morbid psychological distress, compared to those with neither health condition, in a large sample of working Australians.

\section{Methods}

\section{Study design}

The Australian Work Outcomes Research Cost-benefit (WORC) project obtained a large cross-sectional data set of approximately 78,000 working Australians. The WORC dataset was used in this study to explore associations between health and worker productivity, both with and without co-morbid psychological distress. The WORC study has been comprehensively discussed previously $[28,29]$.

\section{Study sample}

The WORC study recruited 58 large Australian-based companies located in both urban and rural Australia. Ten industry groups were included with the largest samples coming from health, education, government, and finance. Data was collected between October 2004 and December 2005.

\section{Study measures}

The study involved the application of the validated World Health Organisation Health and Productivity Questionnaire (HPQ). The HPQ identifies 28 selfreported health conditions [30,31]. It probes selfreported absenteeism and presenteeism rates; and screens for psychological distress using the Kessler 6 (K6) $[2,24]$. Absenteeism was measured by the number of days and part days missed from work in the previous four weeks. Part days were treated as 0.5 day. All days and part days were summed to a total number of days absent. No categories or dichotomized variable was created. Presenteeism was measured using a self-rated score of overall performance in the past four weeks using a $0-10$ scale $(0=$ worst possible performance, $10=$ best possible performance). A series of memory priming and decomposition questions were asked which were applicable across occupations. Then a series of internal anchoring questions followed to enable the respondent to make comparisons with their own average performance and with the performance of their co-workers. Finally, an overall self-reported work performance (presenteeism) score was self-assessed using the same 0-10 scale. This was then categorized into low, average \& high performance and used to measure presenteeism. Most people tend to score themselves highly, therefore the following categories were used: a low score is $<6$, an average score is 6-9 and a high score is 10 [32].

For this study, self-reported health conditions were coded as 'yes' if respondents reported having the condition and either currently or previously having received professional treatment for that condition, and 'no' if they reported never having had the condition. Respondents were excluded if they reported having a condition but never received treatment as these respondents may have incorrectly self-diagnosed the health problem. An average of $0.05 \%$ were excluded per condition. Selfreported conditions included in this study were: arthritis, asthma, back/neck pain, cancers (excluding skin 
cancer), chronic obstructive pulmonary disease (COPD), cardiovascular disease (CVD), drug and alcohol problems, diabetes, fatigue, high blood pressure, high cholesterol, migraine, obesity (BMI score $>31$, calculated from self-reported height and weight), workplace injury in past 12 months that required medical treatment, and psychological distress (being a K6 score of 13 and above). The optimal cut point on the K6 was identified by Kessler as $0-12$ Vs 13 or more. This cut point has a total classification accuracy was 0.92 [33]. A score of 13 or more represents severe psychological distress and indicates the likely presence of a mental health disorder. This cut point was used to create a dichotomous variable to indicate the presence or absence of high psychological distress where scores are $\geq 13$ or $0-12$ respectively. A person was coded as having co-morbid psychological distress if they had a K6 score of 13 or more and had one of the health conditions listed above. The person could have more than one health condition from the above list; this is adjusted for in the multivariate model using the number of co-morbidities covariate as listed below.

The covariates adjusted for in all models were: demographic characteristics of: age, sex, marital status, number of children, education level and annual income; health characteristics of: general treatment seeking behaviour (number of occasions of treatment for any reason except pregnancy, not treatment for a specific condition) and the number of co-morbid conditions; and working condition factors of: occupation, industry, public/private sector, job security (using proxy of part-time or full-time compared to casual), contractor, the rate of workplace accidents per 100 workers in the previous four weeks, hours worked in previous week, supervisory role (number of staff supervised), and hours expected to work in a 7 day week by their employer (as perceived by respondent).

\section{Statistical analysis}

For each health condition, two regression models were developed, one for absenteeism, the other for presenteeism. To account for multiple co-morbidities, models adjusted for the number of co-morbid conditions using the groupings recommended by Kessler (no health conditions, one condition, two-four, five-seven, eight-ten or eleven or more conditions) [32].

For self-reported absenteeism a negative binomial logistic regression statistical procedure was used because it was the most suitable statistical test to cater for a continuous variable with inflated number of zero responses. Presenteeism was modelled using multinomial logistic regressions. The reference category was moderate work performance. High work performance results are not reported here as we are only interested in health associations with under-performance.
To explore the relationship of co-morbid psychological distress with the indexed health condition the variable is separated into three categories as follows: the reference category has neither the indexed health condition nor co-morbid psychological distress (but could also have other health conditions); the second category has the indexed health condition but not co-morbid psychological distress (but could have also other health conditions); and the third category has the indexed health condition and co-morbid psychological distress (and could also have other health conditions).

\section{Results}

The response rate was $24.7 \%$ providing 90,279 responses. From this, a sample of 78,430 workers had complete absenteeism data; and a sample of 77,455 workers had complete presenteeism data. Respondents' demographic characteristics are described in Table 1. The sample included part-time, full-time and casual workers. Approximately $80 \%$ were aged $30-59$ years.

Table 1 Demographic characteristics: 78,430 working Australians

\begin{tabular}{|c|c|}
\hline Demographic Variables & $\%$ \\
\hline \multicolumn{2}{|l|}{$\overline{A G E}{ }^{¥}$} \\
\hline $18-29$ years & 17 \\
\hline $30-44$ years & 43 \\
\hline 45-59 years & 37 \\
\hline 60-70 years & 3 \\
\hline \multicolumn{2}{|l|}{ SEX } \\
\hline Female & 65 \\
\hline Male & 35 \\
\hline \multicolumn{2}{|l|}{ MARITAL STATUS } \\
\hline Separated, divorced, widowed, never married & 29 \\
\hline Married or cohabitating & 71 \\
\hline \multicolumn{2}{|l|}{ NUMBER OF CHILDREN } \\
\hline Nil & 69 \\
\hline 1-3 children & 28 \\
\hline 4 or more children & 3 \\
\hline \multicolumn{2}{|l|}{ EDUCATION LEVEL } \\
\hline Did not complete high school & 14 \\
\hline Completed high school & 10 \\
\hline Some college & 27 \\
\hline Completed college or university & 48 \\
\hline \multicolumn{2}{|l|}{ ANNUAL WAGE $\beta$} \\
\hline$\leq \$ 29999$ pa & 13 \\
\hline \$30000-39999 pa & 14 \\
\hline$\$ 40000-49999$ ра & 21 \\
\hline$\$ 50000-74999$ ра & 36 \\
\hline$\$ 75000-99999$ ра & 10 \\
\hline$\geq \$ 100000 \mathrm{pa}$ & 7 \\
\hline
\end{tabular}

$¥$ : only persons aged 18-70 included in analysis; $\beta$ : excludes hourly rate. $<\$ 7.50$ ph in case fortnightly income reported instead of annual income. 
Sixty five percent were female, which is greater than the proportion in the Australian workforce [34]. The sample also has greater representation of workers from industries of health, education, and government administration; and fewer from retail, construction and mining [34]. The average income and education level are fairly representative of the Australian population [34].

\begin{abstract}
Absenteeism
Compared to the reference category (having neither the indexed condition nor co-morbid psychological distress (PD)), those with the indexed condition had a significantly increased incidence rate ratio (IRR) of absenteeism in unadjusted models (see Table 2). This was the case for all explored health conditions. For example: a person with arthritis but no psychological distress has a $40 \%$ higher risk of absenteeism compared to a person with neither arthritis nor psychological distress. However a person with both arthritis and psychological distress has a $124 \%$ higher risk of absenteeism".

Those with the indexed condition and co-morbid PD also had a greater IRR than the reference category for all conditions explored. The IRR for those with comorbid PD was greater than that of persons with the indexed condition and no co-morbid PD for all conditions explored. Conditions with the highest ranking IRR when not co-morbid with PD were drug and alcohol (IRR: 1.74: CI: 1.30-2.32), COPD, fatigue, injury, arthritis, and cancers. When co-morbid with PD, conditions with the highest ranking IRR were COPD (IRR: 2.80 CI: 1.55-4.92), injury, cancer, D\&A, and arthritis.
\end{abstract}

The IRR effect sizes were reduced in adjusted models (see Table 3). Some health conditions, with or without co-morbid PD, no longer had a significantly increased IRR compared to the reference category (having neither the indexed condition nor co-morbid PD). These were asthma, COPD, CVD, and fatigue. Some conditions only demonstrated a significantly increased IRR when comorbid with PD. These were back/neck pain and migraine. Conditions with the highest IRR effect without co-morbid PD were D\&A (IRR: 1.32 CI: 1.00-1.75), injury, and arthritis. When co-morbid with PD the highest ranking conditions were cancers (IRR: $1.83 \mathrm{CI}$ : 1.44-2.43), injury, and arthritis.

\section{Presenteeism}

In unadjusted models (see Table 4) all health conditions, when co-morbid with PD, had a significantly increased risk compared to the reference category (having neither the indexed condition nor co-morbid PD). Some conditions only had a significantly increased effect size when co-morbid with PD. These conditions were arthritis, cancers, CVD, high blood pressure, and high cholesterol. Conditions with the highest IRR when not co-morbid with PD were D\&A (IRR: 2.57 CI: 2.25-2.94), fatigue, COPD, obesity and injury. Conditions with greatest effect sizes when co-morbid with PD were injury (IRR: 9.46 CI: 7.47-11.99), fatigue, D\&A, arthritis, back/neck pain, diabetes, obesity, and COPD.

All conditions in adjusted models (see Table 5) were associated with an increased IRR when co-morbid with $\mathrm{PD}$, compared to the reference category (having

Table 2 Unadjusted risk of Absenteeism for those with and without co-morbid psychological distress compared to the reference group that had neither the indexed health condition nor co-morbid psychological distress, using negative binomial logistic regression; reporting Incidence Rate Ratios (IRR)

\begin{tabular}{|c|c|c|c|c|c|}
\hline \multirow[b]{2}{*}{ HEALTH CONDITION } & \multirow[b]{2}{*}{ Model n } & \multicolumn{2}{|c|}{ Without co-morbid PD } & \multicolumn{2}{|c|}{ With co-morbid PD } \\
\hline & & $\%$ & IRR (95\%Cls) & $\%$ & IRR (95\%Cls) \\
\hline Arthritis & 64888 & 3.5 & $1.40 * *(1.32-1.49)$ & 0.2 & $2.24^{* *}(1.73-2.92)$ \\
\hline Asthma & 65788 & 6.3 & $1.22^{* *}(1.17-1.28)$ & 0.3 & $1.75^{* *}(1.43-2.14)$ \\
\hline Back/neck pain & 70579 & 29.6 & $1.22^{* *}(1.19-1.25)$ & 1.5 & $2.02^{* *}(1.85-2.21)$ \\
\hline Cancers & 74514 & 3.1 & $1.27^{* *}(1.20-1.35)$ & 0.14 & $2.36^{* *}(1.81-3.08)$ \\
\hline COPD & 71750 & 0.4 & $1.51^{* *}(1.27-1.79)$ & 0.03 & $2.80 *(1.55-4.92)$ \\
\hline CVD & 74002 & 0.8 & $1.17^{*}(1.03-1.32)$ & 0.06 & $2.14^{*}(1.39-3.29)$ \\
\hline Drug \& Alcohol & 72227 & 3.0 & $1.74^{* *}(1.30-2.32)$ & 0.5 & $2.24^{* *}(1.47-3.44)$ \\
\hline Diabetes & 73853 & 2.0 & $1.18^{* *}(1.10-1.27)$ & 0.12 & $1.60 *(1.18-2.16)$ \\
\hline Fatigue/sleep problems & 74630 & 0.6 & $1.48^{* *}(1.29-1.69)$ & 0.10 & $2.08^{* *}(1.51-2.87)$ \\
\hline High Blood Pressure & 71009 & 8.1 & $1.14^{* *}(1.10-1.19)$ & 0.3 & $1.82^{* *}(1.52-2.18)$ \\
\hline High Cholesterol & 68637 & 5.7 & $1.10 * *(1.05-1.16)$ & 0.2 & $1.87^{* *}(1.50-2.32)$ \\
\hline Migraine/severe headache & 70881 & 9.1 & $1.22^{* *}(1.17-1.26)$ & 0.7 & $1.94^{* *}(1.71-2.20)$ \\
\hline Obesity & 71849 & 11.0 & $1.22^{* *}(1.18-1.27)$ & 0.7 & $2.04^{* *}(1.79-2.32)$ \\
\hline Workplace Injury & 75031 & 7.0 & $1.43^{* *}(1.37-1.49)$ & 0.5 & $2.66^{* *}(2.29-3.09)$ \\
\hline
\end{tabular}

*: $p<0.05 ;{ }^{* *}: p<0.001 ; \dagger$ trend $<0.1$. 
Table 3 Adjusted risk of Absenteeism for those with and without co-morbid psychological distress compared to the reference group that had neither the indexed health condition nor co-morbid psychological distress, using negative binomial logistic regression; reporting Incidence Rate Ratios (IRR)

\begin{tabular}{|c|c|c|c|c|c|}
\hline \multirow[b]{2}{*}{ HEALTH CONDITION } & \multirow[b]{2}{*}{ Model $n$} & \multicolumn{2}{|c|}{ Without co-morbid PD } & \multicolumn{2}{|c|}{ 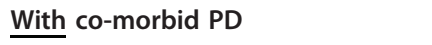 } \\
\hline & & $\%$ & IRR (95\%Cls) & $\%$ & IRR (95\%Cls) \\
\hline Arthritis & 62295 & 3.5 & $1.07^{*}(1.01-1.13)$ & 0.2 & $1.41 *(1.08-1.83)$ \\
\hline Asthma & 63021 & 6.3 & $1.03(0.99-1.08)$ & 0.3 & $1.15(0.94-1.40)$ \\
\hline Back/neck pain & 67715 & 29.6 & $1.02(0.99-1.05)$ & 1.5 & $1.33^{* *}(1.22-1.46)$ \\
\hline Cancers & 71446 & 3.1 & $1.08^{*}(1.02-1.15)$ & 0.14 & $1.83^{* *}(1.44-2.43)$ \\
\hline COPD & 68787 & 0.4 & $1.44(0.96-1.35)$ & 0.03 & $1.63(0.91-2.91)$ \\
\hline CVD & 70954 & 0.8 & $0.96(0.85-1.08)$ & 0.06 & $1.34(0.87-2.06)$ \\
\hline Drug \& Alcohol & 69237 & 3.0 & $1.32 *(1.00-1.75)$ & 0.5 & $1.48^{\dagger}(0.99-2.23)$ \\
\hline Diabetes & 70816 & 2.0 & $0.89 *(0.83-0.96)$ & 0.12 & $1.15(0.85-1.55)$ \\
\hline Fatigue/sleep problems & 71555 & 0.6 & $0.99(0.86-1.13)$ & 0.10 & $1.28(0.93-1.74)$ \\
\hline High Blood Pressure & 68091 & 8.1 & $0.94^{*}(0.90-0.98)$ & 0.3 & $1.19^{\dagger}(1.00-1.42)$ \\
\hline High Cholesterol & 65817 & 5.7 & $0.93^{*}(0.89-0.98)$ & 0.2 & $1.27^{*}(1.03-1.57)$ \\
\hline Migraine/severe headache & 67969 & 9.1 & $1.01(0.97-1.05)$ & 0.7 & $1.29 * *(1.14-1.46)$ \\
\hline Obesity & 68980 & 11.0 & $1.06^{*}(1.02-1.09)$ & 0.7 & $1.33^{* *}(1.17-1.51)$ \\
\hline Workplace Injury & 72095 & 7.0 & $1.19 * *(1.14-1.24)$ & 0.5 & $1.46^{* *}(1.26-1.69)$ \\
\hline
\end{tabular}

Adjusting for: treatment-seeking behaviour, number of co-morbidities, income, industry, public/private sector, occupation, contractor, supervisory role, rate of work accidents per employer, age, education, sex, job security, hours worked in last week, marital status, children, and hours expected to work p.w. (as perceived by employee).

*: $\mathrm{p}<0.05 ;{ }^{* *}: \mathrm{p}<0.001 ;$ † trend $<0.1$.

neither the indexed condition nor co-morbid PD). Some were only significant when co-morbid with PD. These were arthritis, asthma, cancers, diabetes, high cholesterol and migraine. The largest effect sizes for conditions when not co-morbid with PD were for D\&A (IRR: 2.04 CI: 1.16-3.59), fatigue, and obesity. The largest effect sizes compared to the reference category for conditions that were co-morbid with PD were for: arthritis (IRR: 5.06 CI: 3.18-8.05), injury, cancers, and back/neck pain.

\section{Discussion}

Both individual health conditions and conditions when co-morbid with psychological distress had a greater impact on presenteeism than absenteeism in terms of the effect sizes in adjusted models. All health conditions

Table 4 Unadjusted Relative Risk Ratio (RRR) of Presenteeism for those with and without co-morbid psychological distress compared to the reference group that had neither the indexed health condition nor co-morbid psychological distress

\begin{tabular}{|c|c|c|c|c|c|}
\hline \multirow[b]{2}{*}{ HEALTH CONDITION } & \multirow[b]{2}{*}{ Model n } & \multicolumn{2}{|c|}{ Without co-morbid PD } & \multicolumn{2}{|c|}{ With co-morbid PD } \\
\hline & & $\%$ & RRR (95\%Cls) & $\%$ & RRR (95\%Cls) \\
\hline Arthritis & 64079 & 3.5 & $1.10(0.90-1.33)$ & 0.2 & $7.90 * *(5.21-11.97)$ \\
\hline Asthma & 64970 & 6.3 & $1.22^{*}(1.06-1.40)$ & 0.3 & $5.91^{* *}(4.20-8.30)$ \\
\hline Back/neck pain & 69701 & 29.6 & $1.22^{* *}(1.13-1.31)$ & 1.5 & $7.83^{* *}(6.76-9.08)$ \\
\hline Cancers & 73585 & 3.1 & $0.87(0.70-1.08)$ & 0.14 & $7.36^{* *}(4.78-11.34)$ \\
\hline COPD & 70852 & 0.4 & $2.14^{* *}(1.41-3.24)$ & 0.03 & $7.53^{* *}(2.92-19.43)$ \\
\hline CVD & 73083 & 0.8 & $1.47(1.04-2.07)$ & 0.06 & $7.10^{* *}(3.54-14.22)$ \\
\hline Drug \& Alcohol & 74439 & 3.0 & $2.57^{* *}(2.25-2.94)$ & 0.5 & $8.59^{* *}(6.81-10.84)$ \\
\hline Diabetes & 72935 & 2.0 & $1.33^{*}(1.06-1.65)$ & 0.12 & $7.60^{* *}(4.72-12.22)$ \\
\hline Fatigue/sleep problems & 73698 & 0.6 & $2.56^{* *}(1.89-3.46)$ & 0.10 & $8.80^{* *}(5.35-14.46)$ \\
\hline High Blood Pressure & 70119 & 8.1 & $0.90(0.79-1.04)$ & 0.3 & $6.43^{* *}(4.75-8.69)$ \\
\hline High Cholesterol & 67801 & 5.7 & $1.02(0.87-1.19)$ & 0.2 & $7.31^{* *}(5.13-10.41)$ \\
\hline Migraine/severe headache & 69999 & 9.1 & $1.30 * *(1.16-1.45)$ & 0.7 & $7.27^{* *}(5.94-8.90)$ \\
\hline Obesity & 70967 & 11.0 & $1.60^{* *}(1.42-1.73)$ & 0.7 & $7.68^{* *}(6.22-9.48)$ \\
\hline Workplace Injury & 74086 & 7.0 & $1.35^{* *}(1.20-1.53)$ & 0.5 & $9.46^{* *}(7.47-11.99)$ \\
\hline
\end{tabular}

Using multinomial logistic regression, reporting relative risk ratios for low productivity compared to average productivity (high productivity not reported). *: $p<0.05 ;{ }^{* *}: p<0.001 ;+$ trend $<0.1$. 
Table 5 Adjusted Relative Risk Ratio (RRR) of Presenteeism for those with and without

\begin{tabular}{|c|c|c|c|c|c|}
\hline \multirow[b]{2}{*}{ HEALTH CONDITION } & \multirow[b]{2}{*}{ Model $n$} & \multicolumn{2}{|c|}{ Without co-morbid PD } & \multicolumn{2}{|c|}{ With co-morbid PD } \\
\hline & & $\%$ & RRR (95\%Cls) & $\%$ & RRR (95\%Cls) \\
\hline Arthritis & 61081 & 3.5 & $0.90(0.73-1.12)$ & 0.2 & $5.06^{* *}(3.18-8.05)$ \\
\hline Asthma & 61785 & 6.3 & $0.88(0.76-1.02)$ & 0.3 & $2.59^{* *}(1.79-3.75)$ \\
\hline Back/neck pain & 66278 & 29.6 & $0.91 *(0.83-0.99)$ & 1.5 & $4.20^{* *}(3.53-4.99)$ \\
\hline Cancers & 70037 & 3.1 & $0.80^{\dagger}(0.64-1.00)$ & 0.14 & $4.44^{* *}(2.75-7.18)$ \\
\hline COPD & 67437 & 0.4 & $1.43(0.92-2.23)$ & 0.03 & $3.52 *(1.30-9.54)$ \\
\hline CVD & 69564 & 0.8 & $1.17(0.82-1.69)$ & 0.06 & $3.58^{* *}(1.69-7.58)$ \\
\hline Drug \& Alcohol & 67737 & 3.0 & $2.04^{*}(1.16-3.59)$ & 0.5 & $3.23^{* *}(1.64-6.36)$ \\
\hline Diabetes & 69422 & 2.0 & $0.96(0.77-1.22)$ & 0.12 & $3.62^{* *}(2.15-6.10)$ \\
\hline Fatigue/sleep problems & 70146 & 0.6 & $1.47^{*}(1.06-2.04)$ & 0.10 & $3.82^{* *}(2.23-6.56)$ \\
\hline High Blood Pressure & 66741 & 8.1 & $0.81 *(0.69-0.93)$ & 0.3 & $3.65^{* *}(2.63-5.07)$ \\
\hline High Cholesterol & 64532 & 5.7 & $0.87(0.73-1.03)$ & 0.2 & $4.03^{* *}(2.74-5.93)$ \\
\hline Migraine/severe headache & 66632 & 9.1 & $0.90^{\dagger}(0.79-1.02)$ & 0.7 & $3.57^{* *}(2.83-4.49)$ \\
\hline Obesity & 67640 & 11.0 & $1.24^{* *}(1.11-1.38)$ & 0.7 & $3.90 * *(3.08-4.93)$ \\
\hline Workplace Injury & 70682 & 7.0 & $1.11^{\dagger}(0.98-1.27)$ & 0.5 & $4.83^{* *}(3.73-6.25)$ \\
\hline
\end{tabular}

co-morbid psychological distress compared to the reference group that had neither the indexed health condition nor co-morbid psychological distress. Using multinomial logistic regression, reporting relative risk ratios for low productivity compared to average productivity (high productivity not reported)

Adjusting for: number of co-morbidities, treatment-seeking behaviour, age, sex, education, income, marital status, children, income, occupation, industry, public/ private sector, job security, contractor, hours worked in last week, supervisory role, rate of work accidents per employer, hours expected to work p.w. (as perceived by employee).

*: $p<0.05 ;{ }^{* *}: p<0.001 ;+$ trend $<0.1$.

had a greater risk of either absenteeism or presenteeism when co-morbid with psychological distress. The increase in the size of the risk when co-morbid with psychological distress was greater for presenteeism than absenteeism. A larger number of health conditions were associated with significant increased risk of absenteeism when not co-morbid with psychological distress compared to presenteeism (7 and 3 conditions respectively). However, when co-morbid with psychological distress all 14 health conditions were significantly associated with productivity loss for presenteeism compared to 7 of 14 for absenteeism.

These findings suggest a greater than additive effect for some health conditions, particularly those that demonstrate a two-five fold increased IRR. Although the literature on psychological distress is relatively sparse, there is a growing body on depression. Note that the measure of psychological distress is a composite of anxiety, depression, acute grief reactions and various other mental health conditions, and therefore, we are able to link our outcomes with studies that include questionnaires for depression. The literature supports the finding that co-morbid depression can have an additive effect $[18,25]$ and a greater than additive effect $[26,35,36]$. Comorbid physical-mental health problems has reportedly led to a mainly additive increase in work-loss $[18,25]$, reduced likelihood of full-time working status [25], and a significant increase in disability days [25].

The current study found that cancers when co-morbid with psychological distress had a significant impact on productivity losses for both absenteeism and presenteeism; no previous studies have been found that explore the impacts of co-morbid cancer and psychological distress on productivity. Arthritis and workplace injury were both found in our study to be associated with an increased risk of both absenteeism and presenteeism when co-morbid with psychological distress. A study exploring associations with depression across a number of health conditions and their impacts on productivity losses [26] found no significant impact on role impairment when depression is co-morbid with injuries; however, this study found a significant impact on both productivity measures.

Several studies report that co-morbid depression and COPD have a significant impact on productivity loss $[25,37]$. However, in this study the impact was only significant for presenteeism. A review of the link between depressive disorders and health condition reported that obese women had a $50 \%$ increased lifetime prevalence of depressive disorders [22]. No studies were found that explored the impact of obesity co-morbid with psychological distress on productivity. However one study that focused specifically on productivity losses related to obesity adjusted for the number of co-morbid conditions [38]. This indicates the importance of co-morbidity on lost productivity estimates for obesity. The current study found obesity when co-morbid with PD to be significantly associated with both increased presenteeism and absenteeism.

Co-morbid mental disorders and substance use disorders are prevalent in $12 \%$ of people presenting to general 
practice in Australia [39,40]. Those with this co-morbidity were found to have more days out of role than people with either of these conditions in isolation [40] but little is known about the impact of this co-morbidity on productivity. This study found a significant increased Relative Risk Ratio (RRR) of presenteeism when D\&A is comorbid with PD and a trend of increased IRR for absenteeism $(\mathrm{p}=0.06)$.

Co-morbid depression and CVD has been reported to impact on work absence [37] and on role impairment [25]. This study found the impact of psychological distress and CVD was significant for presenteeism only. Consistent with our findings, fatigue has been found to impact on work performance when co-morbid with depression [30]. Depression has been found to have a potential mediating effect on the relationship between fatigue and absenteeism for persons with insomnia [41]. Other studies have adjusted for co-morbid depression when exploring the impacts of fatigue on productivity losses [42-44] demonstrating the importance of co-morbid depression on productivity losses for this condition. This study found fatigue, when co-morbid with PD significantly impacted on presenteeism but not absenteeism.

Some conditions were found to demonstrate a protective effect when considered independently, but many demonstrated an increased likelihood of productivity decrement when co-morbid with psychological distress. These were high blood pressure, and high cholesterol for absenteeism; and back/neck pain and high blood pressure for presenteeism. Diabetes also demonstrated the same pattern but not at a statistically significant effect size. These findings are consistent with the literature in that, employees with depressive illness and either heart disease, diabetes, hypertension or back problems were found to cost the employer 1.7 times more than those with the comparative condition alone [27]. One study found that employees with diabetes had a 2.15 -fold excess risk of absenteeism but that up to $55 \%$ was attributable to depression and only $7 \%$ was purely attributable to diabetes [35].

There are some limitations to our study that need to be considered. Associations between factors were determined in this cross-sectional study; however, no conclusions can be drawn regarding causal pathways. The sample has more white-collar workers than the general population. Industry type and work role were included in models to adjust for these potential differences; however, extrapolation of these findings to the general employed population should be undertaken only where there is a clear match in the demographics of any subgroup. It should also be considered that only those at work during the data collection period responded. It could be that people on extended sick leave or out of the workforce are not represented. This may explain our cancer results, as other studies have demonstrated a strong association between productivity losses and cancer [1]. Other limitations include the self-reported nature of health conditions, the over-representation of females, the absence of some top burden of disease conditions such as kidney diseases, and the absence of some relevant work-related characteristics such as decisionmaking control. In addition, the survey was conducted from October 2004 to December 2005 and included one summer holiday season over the Christmas and New Year period in Australia. We were unable to control for any potential seasonal effects as many participants did not include the date the survey was completed. Nevertheless, many parts of Australia are tropical and sub-tropical, so the seasonal effects on illness are less pronounced compared with temperate climates. Strengths of the study include the large sample size, the range of data available relating to health conditions, work-related characteristics, demographic characteristics and the sample representing regional, rural and urban Australia.

This research raises the question of whether psychological distress is a potential mediating factor in lost productivity. Although with cross-sectional data we cannot conclusively answer this question; our findings highlight to need for further research into whether psychological distress, a treatable condition, may well exacerbate productivity losses. There is now strong evidence for the association between mental health problems, particularly depression, and other health conditions [16,21,45]; and between depression and productivity loss [5,46-48].

\section{Conclusions}

This research suggests that psychological distress is an exacerbating factor in lost productivity. Given the evidence for a growing prevalence of psychological distress [49], and the role this plays in mediating sickness absence for other diseases [50], including chronic back pain and arthritis [51], this area is an important one for further research with appropriate study designs, to enable the development of interventions that can be applied to the wider community.

\section{List of abbreviations}

Cl: Confidence intervals; COPD: Chronic obstructive pulmonary disease; CVD: Cardio-vascular disease; D\&A: Drug and alcohol problems; HPQ: World Health Organisation Health and Productivity Questionnaire; IRR: Incidence rate ratio; K6: Kessler 6 (Psychological Distress questionnaire); PD: Psychological distress; RRR: relative risk ratio; WORC: Australian Work Outcomes Research Costbenefits (WORC) study

\section{Acknowledgements}

The authors would like to acknowledge the contribution of Professor Ron Kessler and Dr. Philip Wang for their guidance in establishing the study protocol and Cathy Cleary and Judith Sheridan for implementation of the 
protocol. This work was financially supported by (1) the Department of Health and Ageing, Mental Health Strategy Branch, Australian Government, Canberra, ACT. (2) beyondblue: the national depression initiative, Melbourne, VIC, Australia (3) The Australian Rotary Health Research Fund, Paramatta, NSW, Australia.

\section{Author details}

'School of Medicine, Griffith University; University Drive Meadowbrook, Queensland 4131, Australia. ${ }^{2}$ Queensland Centre for Mental Health research, Queensland Health; Level 3 Dawson house, The Park, Wacol, Queensland 4076, Australia. ${ }^{3}$ University of Queensland, School of Population Health; Herston Road Herston, Queensland 4006, Australia.

\section{Authors' contributions}

LH developed the methods for this study in collaboration with coinvestigators, conducted data analysis with help from statistician, wrote first draft and revisions to paper, corresponding author; PS assisted with developing methods, advised on statistical analysis methods, and reviewed drafts of paper; $\mathrm{MH}$ coordinated data collection and reviewed drafts of paper. RW assisted with data analysis and reviewed drafts of paper; NV assisted with developing methods for this study and reviewed drafts of paper; and HW chief investigator of parent study which collected the data used in this study and reviewed drafts of paper. All co-authors read and approved the final manuscript.

\section{Competing interests}

The authors declare that they have no competing interests.

Received: 17 September 2010 Accepted: 31 May 2011

Published: 31 May 2011

\section{References}

1. Kessler R, Greenberg P, Mickelson K, Meneades L, Wang P: The Effect of Chronic Medical Conditions on Work Loss and Work Cutback. Journal of Occupational and Environmental Medicine 2001, 43:218-225.

2. Kessler R, Barber C, Beck A, Berglund P, Cleary P, McKenas D, Pronk N, Simon G, Stang P, Ustun T, et al: The World Health Organisation Health and Work Performance Questionnaire (HPQ). Journal of Occupational and Environmental Medicine 2003, 45:156-174.

3. Stewart WF, Ricci JA, Chee JA, Morganstein D: Lost Productive Work Time Costs From Health Conditions in the United States: Results from the American Productivity Audit. Journal of Occupational and Environmental Medicine 2003, 45:1234-1246.

4. Guthrie R, Meredith F: Long-term employee illness and frustration of the contract of employment. Journal of Industrial Relations 2007, 49(1):87-101.

5. Wang PS, Beck A, Berglund P, Pronk N, Richling D, Scheenk T, Simon GE, Stang $P$, Ustun T, Kessler R: Chronic medical conditions and work performance in the health and work performance questionnaire calibration. Journal of Occupational and Environmental Medicine 2003, 45(12):1303-1311.

6. Merikangas KR, Ames M, Cui L, Stang PE, Ustun TB, Von Korff M, Kessler RC: The impact of comorbidity of mental and physical conditions on role disability in the US adult household population. Arch Gen Psychiatry 2007, 64:(10):1180-1188.

7. Burton W, Pransky GS, Conti D, Chen C, Edington D: The association of medical conditions and presenteeism. J Occup Environ Med 2004, 46 S38-S45.

8. Goetzel R, Hawkins K, Ozminkowski R, Wang S: The health and productivity cost burden of the "Top 10" physical and mental health conditions affecting six large US employers in 1999. Journal of Occupational and Environmental Medicine 2003, 45(1):5-14.

9. Goetzel R, Long S, Ozminkowski R, Hawkins K, Wang S, Lynch W: Health, Absence, Disability an presenteeism cost estimates of certain physical and mental health conditions affecting US employers. Journal of Occupational and Environmental Medicine 2004, 46:398-412.

10. White A, Birnbaum H, Mareva M, Henckler B, Grossman P, Mallet D: Economic burden of illness for employees with painful conditions. J Occup Environ Med 2005, 47:884-892.

11. Collins JJ, Baase CM, Sharda CE, Ozminkowski RJ, Nicholson S, Billotti GM, Turpin RS, Olson M, Berger ML: The assessment of chronic health conditions on work performance, absence, and total economic impact for employers. J Occup Environ Med 2005, 47(6):547-557.

12. Dew K, Keefe V, Small K: 'Choosing' to work when sick: workplace presenteeism. Soc Sci Med 2005, 60:2273-2282.

13. Fortin M, Bravo G, Hudon C, Vanasse A, Lapointe L: Prevalence of multimorbidity among adults seen in family practice. Annals of Family Medicine 2005, 3:223.

14. van den Akker M, Buntinx F, Roos S, Knottnerus J: Problems in determining occurrence rates of multimorbidity. Journal of Clinical Epidemiology 2001, 54(7):675-679.

15. van den Akker M, Buntinx F, Metsemakers JF, Roos S, Knottnerus JA: Multimorbidity in general practice: prevalence, incidence, and determinants of co-occurring chronic and recurrent diseases. J Clin Epidemiol 1998, 51(5):367-375.

16. Moussavi S, Chatterji S, Verdes E, Tandon A, Patel V, Bedirhan U: Depression, chronic disease, and decrements in health: results from the World Health Surveys. The Lancet 2007, 370(September 8):851-858.

17. Crews CK, Vu KO, Davidson AJ, Crane LA, Mehler PS, Steiner JF: Podiatric problems are associated with worse health status in persons with severe mental illness. General Hospital Psychiatry 2004, 26(3):226-232.

18. Demyttenaere K, Bonnewyn A, Bruffaerts R, Brugha T, De Graaf R, Alonso J: Comorbid painful physical symptoms and depression: Prevalence, work loss, and help seeking. Journal of Affective Disorders 2006, 92(2-3):185-193.

19. Benton T, Staab J, Evans DL: Medical co-morbidity in depressive disorders. Annals of Clinical Psychiatry 2007, 19(4):289-303.

20. Fortin M, Bravo G, Hudon C, Lapointe L, Dubois M-F, Almirall J: Psychological Distress and Multimorbidity in Primary Care. Annals of Family Medicine 2006, 5(September-October):417-422.

21. Nuyen J, Schellevis FG, Satariano WA, Spreeuwenberg PM, Birkner MD, van den Bos GA, Groenewegen PP: Comorbidity was associated with neurologic and psychiatric diseases: a general practice-based controlled study. Journal of Clinical Epidemiology 2006, 59(12):1274-1284.

22. Chapman D, Perry G, Strine T: The vital link between chronic disease and depressive disorders. Preventing Chronic Disease: Public Health Research, Practice, and Policy 2005, 2(1)

23. Australian Bureau of Statistics: Mental Health in Australia-a snapshot 2004-05.Edited by: Statistics ABo. Canberra: Australian Bureau of Statistics; 2006:

24. Kessler R, Andrews G, Colpe L, Hirip E, Mroczek D, Normand S, Walters E, AM Z: Short screening scales to monitor population prevalences and trends in non-specific psychological distress. Psychological Medicine 2002, 32:959-976.

25. Baune BT, Adrian I, Jacobi F: Medical disorders affect health outcome and general functioning depending on comorbid major depression in the general population. Journal of Psychosomatic Research 2007, 62(2):109-118.

26. Buist-Bouwman MA, de Graaf R, Vollebergh WA, Ormel J: Comorbidity of physical and mental disorders and the effect on work-loss days. Acta Psychiatr Scand 2005, 111(6):436-443.

27. Druss B, Rosenheck R, Sledge W: Health and Disability Costs of Depressive IIIness in a Major U.S. Corporation. American Journal of Psychiatry 2000 157:1274-1278.

28. Hilton M, Whiteford H, Sheridan J, Cleary C, Chant D, Wang P, Kessler R: Prevalence of psychological distress in employees and associated occupational risk factors. Journal of Occupational and Environmental Medicine 2008, 50(7):747-757.

29. Hilton MF, Sheridan J, Cleary CM, Whiteford H: Employee absenteeism measure reflecting current work practices may be instrumental in the re-evaluation of the relationship between psychological distress/mental health and absenteeism. International Journal of Methods in Psychiatric Research 2009, 18(1):37-47.

30. Kessler R, White LA, Birnbaum H, Qiu Y, Kidolezi Y, Mallett D, Swindle R: Comparative and interactive effects of depression relative to other health problems on work performance in the workforce of a large employer. Journal of Occupational and Environmental Medicine 2008, 50(7):809-816.

31. Kessler RC, Barber C, Beck A, Berglund P, Cleary PD, McKenas D, Pronk N, Simon G, Stang P, Ustun TB, et al: The World Health Organization Health and Work Performance Questionnaire (HPQ). Journal of Occupational and Environmental Medicine 2003, 45(2):156-174.

32. Kessler R, Ames M, Hymel P, Loeppke R, McKenas D, Richling D, Stang P, Ustun T: Using the World Health Organisation Health and Work 
Performance Questionnaire (HPQ) to evaluate the indirect workplace costs of illness. Journal of Occupational and Environmental Medicine 2004, 46(6 suppl):S23.

33. Kessler R, Barker P, Colpe L, Epstien J, Gfroerer J, Hiripi E, Howes M, Normand SL, Maunderscheid R, Walters E, et al: Screening for Serious Mental IIIness in the General Population. Archives of General Psychiatry 2003, 60:184-189.

34. Australian Bureau of Statistics: Year book Australia, 2008.Edited by: Statistics ABo. Canberra: Australian Government; 20081301.0.

35. Kivimaki M, Vahtera J, Pentti J, Virtanen M, Elovainio M, Hemingway H: Increased sickness absence in diabetic employees: what is the role of co-morbid conditions? Diabetic Medicine 2007, 24(9):1043-1048.

36. Munce SEP, Stansfeld SA, Blackmore ER, Stewart DE: The role of depression and chronic pain conditions in absenteeism: results from a national epidemiologic survey. Journal of Occupational and Environmental Medicine 2007, 49(11):1206-1211.

37. Stein M, Cox B, Afifi T, Belik SL, Sareen J: Does comorbid depressive illness magnify the impact of chronic physical illness? A population-based perpective. Psychological Medicine 2006, 36:587-596.

38. Ricci JA, Chee E: Lost productive time associated with excess weight in the U.S. workforce. J Occup Environ Med 2005, 47(12):1227-1234.

39. Marshall KL, Deane FP: General practitioners' detection and management of patients with a dual diagnosis: implications for education and training. Drug Alcohol Rev 2004, 23(4):455-462.

40. Hickie IB, Koschera A, Davenport TA, Naismith SL, Scott EM: Comorbidity of common mental disorders and alcohol or other substance misuse in Australian general practice. Med J Aust 2001, 175(Suppl):S31-36.

41. Philip P, Leger D, Taqillard J, Quera-Salva MA, Niedhammer I, Mosqueda J, Bioulac B, Gerard D: Insomniac complaints interfere with quality of life but not with absenteeism: respective role of depression and organic comorbidity. Sleep Medicine 2006, 7:585-591.

42. Bultmann U, Huibers MJH, van Amelsvoort LGPM, Kant IJ, Kasl SV, Swaen GMH: Psychological Distress, Fatigue and Long-Term Sickness Absence: Prospective Results From the Maastricht Cohort Study. Journal of Environmental Medicine 2005, 47(9):941-947.

43. Huibers MJ, Bultmann U, Kasl SV, Kant I, van Amelsvoort LG, van Schayck CP, Swaen GM: Predicting the two-year course of unexplained fatigue and the onset of long-term sickness absence in fatigued employees: results from the Maastricht Cohort Study. J Occup Environ Med 2004, 46(10):1041-1047.

44. Nakata A, Haratani T, Takahashi M, Kawakami N, Arito H, Kobayashi F, Fujioka Y, Fukui S, Araki S: Association of sickness absence with poor sleep and depressive symptoms in shift workers. Chronobiol Int 2004, 21(6):899-912.

45. Australian Institute of Health \& Welfare: Australia's Health 2006. In AlHW Cat No AUS73 Edited by: AlHW 2006.

46. Simon G, Barber C, Birnbaum H, Frank R, Greenberg P, Rose R, Wang P, Kessler R: Depression and Work Productivity: The Comparative Costs of Treatment Versus Nontreatment. Journal of Occupational and Environmental Medicine 2001, 43:2-9.

47. Laitinen-Krispijn S, Bijl RV: Mental disorders and employee sickness absence: the NEMESIS study. Netherlands Mental Health Survey and Incidence Study. Social Psychiatry and Psychiatric Epidemiology 2000, 35(2):71-77.

48. Simon G: Social and economic burden of mood disorders. Society of Biological Psychiatry 2003, 54:208-215.

49. Australian Institute of Health \& Welfare: Australia's Health 2008.Edited by: AlHW 2008.

50. Savikko A, Alexanderson K, Hensing G: Do mental health problems increase sickness absence due to othe diseases. Journal of Scial Psychiatric Epidemiology 2001, 36:310-316.

51. Waghorn G, Chant D, Lloyd C: Labor force activity among Australians with musculoskeletal disorders comorbid with depression and anxiety disorders. J Occup Rehabil 2006, 16(2):241-252.

Pre-publication history

The pre-publication history for this paper can be accessed here: http://www.biomedcentral.com/1471-2458/11/417/prepub

doi:10.1186/1471-2458-11-417

Cite this article as: Holden et al: Health-related productivity losses increase when the health condition is co-morbid with psychological distress: findings from a large cross-sectional sample of working Australians. BMC Public Health 2011 11:417.

\section{Submit your next manuscript to BioMed Central and take full advantage of:}

- Convenient online submission

- Thorough peer review

- No space constraints or color figure charges

- Immediate publication on acceptance

- Inclusion in PubMed, CAS, Scopus and Google Scholar

- Research which is freely available for redistribution

Submit your manuscript at www.biomedcentral.com/submit
C Biomed Central 